\begin{abstract}
Iranica
Abstracta Iranica Revue bibliographique pour le domaine irano-aryen

Volume 34-35-36 | 2017

Comptes rendus des publications de 2011-2013
\end{abstract}

\title{
Ludwig Paul. Handbuch der Iranistik
}

\section{Agnes Korn}

\section{OpenEdition}

Journals

Édition électronique

URL : http://journals.openedition.org/abstractairanica/42408

DOI : 10.4000/abstractairanica.42408

ISSN : 1961-960X

Éditeur :

CNRS (UMR 7528 Mondes iraniens et indiens), Éditions de l'IFRI

\section{Référence électronique}

Agnes Korn, « Ludwig Paul. Handbuch der Iranistik», Abstracta Iranica [En ligne], Volume 34-35-36 | 2017, document 5, mis en ligne le 30 juillet 2017, consulté le 26 septembre 2020. URL : http:// journals.openedition.org/abstractairanica/42408; DOI : https://doi.org/10.4000/abstractairanica. 42408

Ce document a été généré automatiquement le 26 septembre 2020.

Tous droits réservés 


\title{
Ludwig Paul. Handbuch der Iranistik
}

\author{
Agnes Korn
}

\section{RÉFÉRENCE}

Ludwig Paul. Handbuch der Iranistik. Wiesbaden, Reichert, 2013, 488 p. [http://

reichert-verlag.de/fachgebiete/sprachwissenschaft/

sprachwissenschaft_indogermanistik/9783895009181_handbuch_der_iranistik-detail]

1 Ce volume, entièrement en allemand, se veut un manuel accessible non seulement aux spécialistes, mais abordable aussi par tous ceux qu'intéresse l'iranologie. Il part du constat que depuis la parution du Grundriss der iranischen Philologie 1895-1904 aucun ouvrage n'a essayé de faire le tour des langues et des cultures iraniennes. Étant donné l'avancement de nos connaissances et la disponibilité de données survenus depuis la publication du Grundriss, il était urgent de contribuer à combler cette lacune.

2 Fidèle à la fois à son approche compréhensive et à l'objectif d'être utile à un public large, le présent volume comprend huit parties: Histoire ; Époque actuelle; Droit ; Religion ; Langues ; Littérature ; Codicologie ; Archéologie, art et architecture. Chacune des parties regroupe des chapitres s'étalant sur une petite dizaine à une vingtaine de pages et rédigés par des spécialistes du sujet, suivant un plan que l'éditeur décrit dans son introduction : présentation des aspects et des questions qui, dans le cadre du sujet particulier, sont actuellement au centre des recherches et ont donné lieu à des discussions et des études. Les chapitres sont donc introduits par (A.) une esquisse de méthode dans ses principaux aspects, avec les données et les sources disponibles, destinée à donner au lecteur une impression générale du sujet avant de fournir (B.) un rapport des résultats principaux des recherches et (C.) une bibliographie.

Ce nouveau « Manuel d'iranologie » offre, d'une façon tout à fait maniable et claire, une mise à jour des connaissances sur un vaste panorama des sujets étudiés. Il est complété d'une annexe de cartes et d'un tableau survolant les époques, ainsi que des indexes. 


\section{AUTEURS}

\section{AGNES KORN}

CNRS, Mondes iranien et indien 